\title{
RESEARCH ON THE BODY-MASS INDEX OF THE BODY AND THE BODY CIRCUMFERENCE IN THE CURRENT SECTION OF THE EQUAL ROTATION MOMENTS OF THE UPPER AND LOWER PART OF THE BODY
}

\author{
A. Atanasov $^{1}$, N. Pirovski ${ }^{1 *}$, D. Valev ${ }^{3}$ \\ ${ }^{1}$ Faculty of Medicine, Trakia University, Stara Zagora, Bulgaria \\ ${ }^{2}$ Space Research and Technology Institute, BAS
}

\begin{abstract}
The bed-scales determine the section in which the torques of the upper and lower body is balanced. In this section, body circumference is measured and a relationship is sought between body circumference and body mass parameters $(\mathrm{M}, \mathrm{kg})$, body height $(\mathrm{H}, \mathrm{m})$, and body mass index (BMI, $\left.\mathrm{kg} / \mathrm{m}^{2}\right)$. Aim of the study: Investigate the relationship between the circumference of the body in the cross section of the equal torques of the upper and the lower body and the body mass index of the body. Results: 64 people between the ages of 18 and 28 were examined. The high correlation coefficient between the body circumference and body mass and BMI, as well as low correlation coefficient between body circumference and body height were obtained. Conclusions: There is no statistically significant relationship between body circumference and height. At different body heights, equal body circumferences can be observed.
\end{abstract}

Key words: body center, body circumference, BMI, body rotation

\section{INTRODUCTION}

It is known that body mass index can be an indicator of health, and functional status, quality of life and risk of mortality in different age groups. In addition to the body mass index, the waist, hips , and chest circumference of the human body are also used as indicators of health status. They are an objective indicator of diseases mainly related to overweight and the risk of cardiovascular disease [1]. In the previous study Atanasov [2] developed a method for measuring the center of the mass [3] of the human body using a BED-SCALES device (Figure 1).

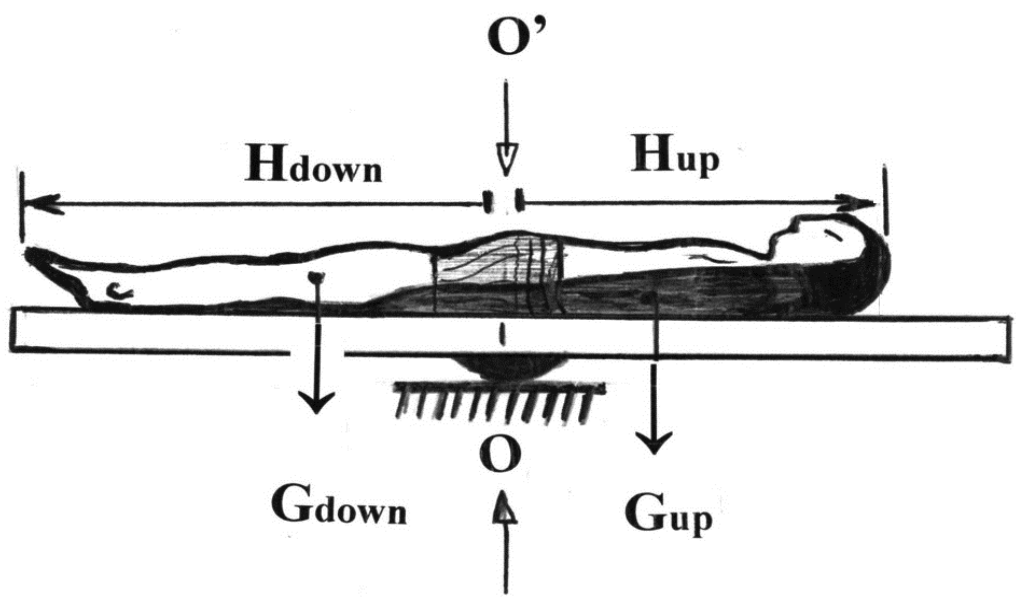

Figure 1. Bed-scales. The circumference of the body $\mathrm{L}$ in the cross section of the equal torques $\mathrm{O}-\mathrm{O}$ 'of the upper and lower part of the body.

\footnotetext{
*Correspondence to: $N$. Pirovski, Medical Faculty,

Trakia University, e-mail: pirovsky@abv.bg
} 
The bed-scales determine the section, in which the torques of the upper and lower part of the body is balanced (see section O-O'). In this section the body circumference is measured and a connection is sought between the measured body circumference and the parameters - body weight ( $\mathrm{M}, \mathrm{kg})$, body height $(\mathrm{H}, \mathrm{m})$ and body mass index (BMI, $\left.\mathrm{kg} / \mathrm{m}^{2}\right)$. Indeed, Figure 1 shows that:

$\mathrm{G}_{\text {up }} \mathrm{H}_{\text {up }}=\mathrm{G}_{\text {down }} \mathrm{H}_{\text {down }}$

$\mathrm{H}=\mathrm{H}_{\text {up }}+\mathrm{H}_{\text {down }}$

$\mathrm{G}=\mathrm{G}_{\text {up }}+\mathrm{G}_{\text {down }}$

Where $G, G_{\text {up }}$ and $G_{\text {down }}$ are the mass of the whole body, of the upper body and of the lower body, respectively. $\mathrm{H}$, Hup and $\mathrm{H}_{\text {down }}$ are the height of the whole body, the upper and the lower part of the body, respectively. The works $\mathrm{G}_{\text {up }} \mathrm{H}_{\text {up }}$ and $\mathrm{G}_{\text {down }} \mathrm{H}_{\text {down }}$ are the torques of the upper and lower body parts.

In the section $\mathrm{O}-\mathrm{O}$ ', in which the torques GupHup and Gdown Hdown are equal, the circumference of the body $\mathrm{L}$ is measured, with the help of which the center of gravity of the body is determined.

\section{AIM OF THE STUDY}

To study the relationship between the circumference of the body in the cross section of the equal torques of the upper and lower body and the body mass index of the body.

\section{MATERIALS AND METHODS}

64 people aged between 18 and 30 of both sexes ( 24 men and 40 women) were studied.

1. Measure the mass of the body $\mathrm{M}$, the height of the body $\mathrm{H}$, the circumference of the body $\mathrm{L}$ in the cross section of the equal torques.

2. Calculate the body mass index.

3. The statistical relationship between body circumference, mass, height and body mass index is studied.

4. The statistical relationship between body weight and height is studied.

5. The statistical program STATISTICS is used in the calculations.

6. The statistical significance $p$ of the found correlations was determined using Student's ttest.

\section{RESULTS}

The measured parameters - bodyweight $\mathrm{M}$, body height $\mathrm{H}$, body circumference $\mathrm{L}$ and calculated BMI values of the body are given in Table 1. The statistical sample of data for men and women in Table $\mathbf{1}$ is not homogeneous (24 men against 40 women). For this reason, differentiating the result only for men and only for women will not be statistically significant. That's why we look at the two sexes together.

Table 1. BMI and circumference of the body in the cross section of equal torques.

\begin{tabular}{|l|l|l|l|l|}
\hline $\mathrm{N}$ & $\begin{array}{l}\text { Mass ( kg) } \\
\text { man-(m) } \\
\text { woman-(w) }\end{array}$ & Height (m) & BMI $\left(\mathrm{kg} / \mathrm{m}^{2}\right)$ & $\begin{array}{l}\text { Circumference of the body L in } \\
\text { the cross section of equal torques } \\
(\mathrm{m})\end{array}$ \\
\hline 1 & $75(\mathrm{~m})$ & 1.87 & 21.44 & 87 \\
\hline 2 & $44(\mathrm{w})$ & 1.60 & 17.1875 & 77 \\
\hline 3 & $102(\mathrm{~m})$ & 1.84 & 30.1275 & 109 \\
\hline 4 & $97(\mathrm{~m})$ & 1.83 & 28.9647 & 101 \\
\hline 5 & $57.9(\mathrm{w})$ & 1.57 & 23.4897 & 96 \\
\hline 6 & $54.4(\mathrm{w})$ & 1.55 & 22.64 & 95 \\
\hline 7 & $70(\mathrm{~m})$ & 1.74 & 23.12 & 85 \\
\hline 8 & $59.3(\mathrm{w})$ & 1.75 & 19.36 & 98 \\
\hline 9 & $64.8(\mathrm{w})$ & 1.74 & 21.40 & 96.5 \\
\hline 10 & $69.7(\mathrm{~m})$ & 1.64 & 25.91 & 107 \\
\hline 11 & $56(\mathrm{w})$ & 1.65 & 20.57 & 96 \\
\hline 12 & $64(\mathrm{~m})$ & 1.83 & 19.11 & 78 \\
\hline 13 & $52.1(\mathrm{w})$ & 1.66 & 18.906 & 91 \\
\hline 14 & $63.9(\mathrm{w})$ & 1.66 & 23.189 & 90 \\
\hline 15 & $103(\mathrm{~m})$ & 1.7 & 35.64 & 126 \\
\hline 16 & $66.6(\mathrm{w})$ & 1.7 & 23 & 96 \\
\hline 17 & $73.5(\mathrm{~m})$ & 1.8 & 22.685 & 96 \\
\hline 18 & $51(\mathrm{w})$ & 1.69 & 17.857 & 81 \\
\hline 19 & $43.8(\mathrm{w})$ & 1.56 & 17.998 & 86 \\
\hline
\end{tabular}


ATANASOV A., et al.

\begin{tabular}{|c|c|c|c|c|}
\hline 20 & $67.3(\mathrm{w})$ & 1.73 & 22.485 & 95 \\
\hline 21 & $63 \quad(\mathrm{~m})$ & 1.78 & 19.88 & 89 \\
\hline 22 & $63.5(w)$ & 1.65 & 23.32 & 96 \\
\hline 23 & $86.5(\mathrm{~m})$ & 1.88 & 24.47 & 105 \\
\hline 24 & $81 \quad(\mathrm{~m})$ & 1.83 & 24.187 & 96 \\
\hline 25 & $82 \quad(\mathrm{~m})$ & 1.77 & 26.17 & 101 \\
\hline 26 & $95 \quad(\mathrm{~m})$ & 1.9 & 26.315 & 106 \\
\hline 27 & $81 \quad(\mathrm{~m})$ & 1.78 & 25.564 & 105 \\
\hline 28 & $93 \quad(\mathrm{~m})$ & 1.75 & 30.367 & 93 \\
\hline 29 & $86 \quad(\mathrm{~m})$ & 1.85 & 25.128 & 97 \\
\hline 30 & $73 \quad(\mathrm{~m})$ & 1.83 & 21.798 & 90 \\
\hline 31 & $55 \quad(w)$ & 1.73 & 18.377 & 88 \\
\hline 32 & $76 \quad(\mathrm{~m})$ & 1.88 & 21.50 & 99 \\
\hline 33 & $90 \quad(\mathrm{~m})$ & 1.88 & 25.46 & 100 \\
\hline 34 & $50.7(w)$ & 1.59 & 20.05 & 87 \\
\hline 35 & $74 \quad(w)$ & 1.6 & 28.906 & 109 \\
\hline 36 & $58 \quad(\mathrm{w})$ & 1.55 & 24.14 & 84 \\
\hline 37 & $88 \quad(\mathrm{~m})$ & 1.74 & 29.065 & 98 \\
\hline 38 & $60 \quad(w)$ & 1.64 & 22.30 & 95 \\
\hline 39 & $110(\mathrm{~m})$ & 1.81 & 33.57 & 115 \\
\hline 40 & $56 \quad(w)$ & 1.54 & 23.61 & 95 \\
\hline 41 & $95 \quad(\mathrm{~m})$ & 1.79 & 29.65 & 102 \\
\hline 42 & $55 \quad(w)$ & 1.56 & 22.6 & 90 \\
\hline 43 & $54 \quad(w)$ & 1.70 & 18.685 & 95 \\
\hline 44 & $54 \quad(w)$ & 1.7 & 18.685 & 87 \\
\hline 45 & $54 \quad(w)$ & 1.59 & 21.36 & 91 \\
\hline 46 & $55 \quad(\mathrm{w})$ & 1.60 & 21.484 & 98 \\
\hline 47 & $60 \quad(w)$ & 1.65 & 22.038 & 93 \\
\hline 48 & $59.5(\mathrm{w})$ & 1.63 & 22.394 & 97 \\
\hline 49 & $104(\mathrm{~m})$ & 1.8 & 32.1 & 121 \\
\hline 50 & $63(\mathrm{w})$ & 1.68 & 22.32 & 96 \\
\hline 51 & $75.5(\mathrm{~m})$ & 1.84 & 22.30 & 104 \\
\hline 52 & $55 \quad(\mathrm{w})$ & 1.72 & 18.591 & 89 \\
\hline 53 & $67 \quad(w)$ & 1.70 & 23.18 & 101 \\
\hline 54 & $57 \quad(\mathrm{w})$ & 1.65 & 20.936 & 89 \\
\hline 55 & $83 \quad(w)$ & 1.60 & 32.422 & 118 \\
\hline 56 & $52 \quad(w)$ & 1.54 & 21.93 & 94 \\
\hline 57 & $47 \quad(w)$ & 1.64 & 17.475 & 85 \\
\hline 58 & $54 \quad(w)$ & 1.63 & 20.32 & 88 \\
\hline 59 & $90 \quad(w)$ & 1.62 & 34.293 & 118 \\
\hline 60 & $60 \quad(w)$ & 1.5 & 26.66 & 102 \\
\hline 61 & $59 \quad(w)$ & 1.65 & 21.671 & 95 \\
\hline 62 & $62 \quad(w)$ & 1.63 & 23.335 & 98 \\
\hline 63 & $51 \quad(\mathrm{w})$ & 1.54 & 21.5 & 84 \\
\hline 64 & $47 \quad(w)$ & 1.58 & 18.827 & 87 \\
\hline
\end{tabular}

The calculated BMI from Table 1 of the age group between 18 and 30 years falls in the range from $17 \mathrm{~kg} / \mathrm{m}^{2}$ to $34 \mathrm{~kg} / \mathrm{m}^{2}$. These values range from lean people with an underweight body mass index (BMI <19) to overweight people (BMI> 34). This wide range of body mass indices contributes to the objectivity of the dependences obtained below from Figure 2
A parametric linear regression analysis of the statistical relationship between body parameters (a, b, c, d) was performed:

a. Circumference (L) and body mass of the subjects (M) - Figure 2.

b. Circumference (L) and body height of the subjects $(\mathrm{H})$ - Figure 3.

\section{to Figure 5.}


c. Circumference (L) and body mass index of the subjects (BMI) - Figure 4.

d. Body mass (M) and body height of the subjects $(\mathrm{H})$ - Figure 5.

Student $\mathrm{t}$-test was performed for each of these $4(\mathrm{a}, \mathrm{b}, \mathrm{c}, \mathrm{d})$ regression relationships.

It was found that with the exception of the relationship between circumference (L) and body height $(\mathrm{H})$, the remaining relationships
ATANASOV A., et al.

were statistically significant with a level of statistical significance $\mathrm{p}<0.00001$.

In Figure 2, the relationship between body circumference and body mass is presented. Figure 3 shows the relationship between body circumference and body height. Figure $\mathbf{4}$ shows the relationship between body circumference and body mass index. Figure $\mathbf{5}$ shows the relationship between body weight and body height. All figures are presented on a linear scale.

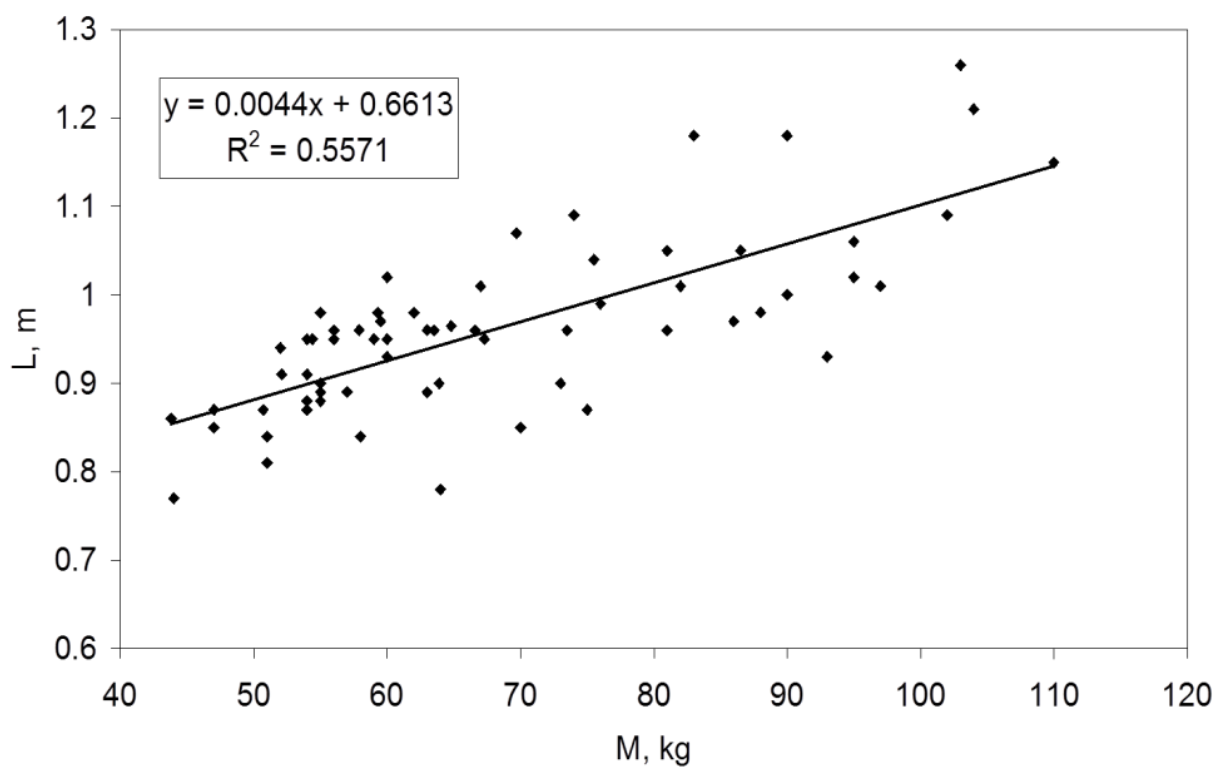

Figure 2. Dependence between the circumference length $\mathrm{L}(\mathrm{m})$ and the mass $\mathrm{M}(\mathrm{kg})$ of the subjects. Level of statistical significance $\mathrm{p}<0.00001$.

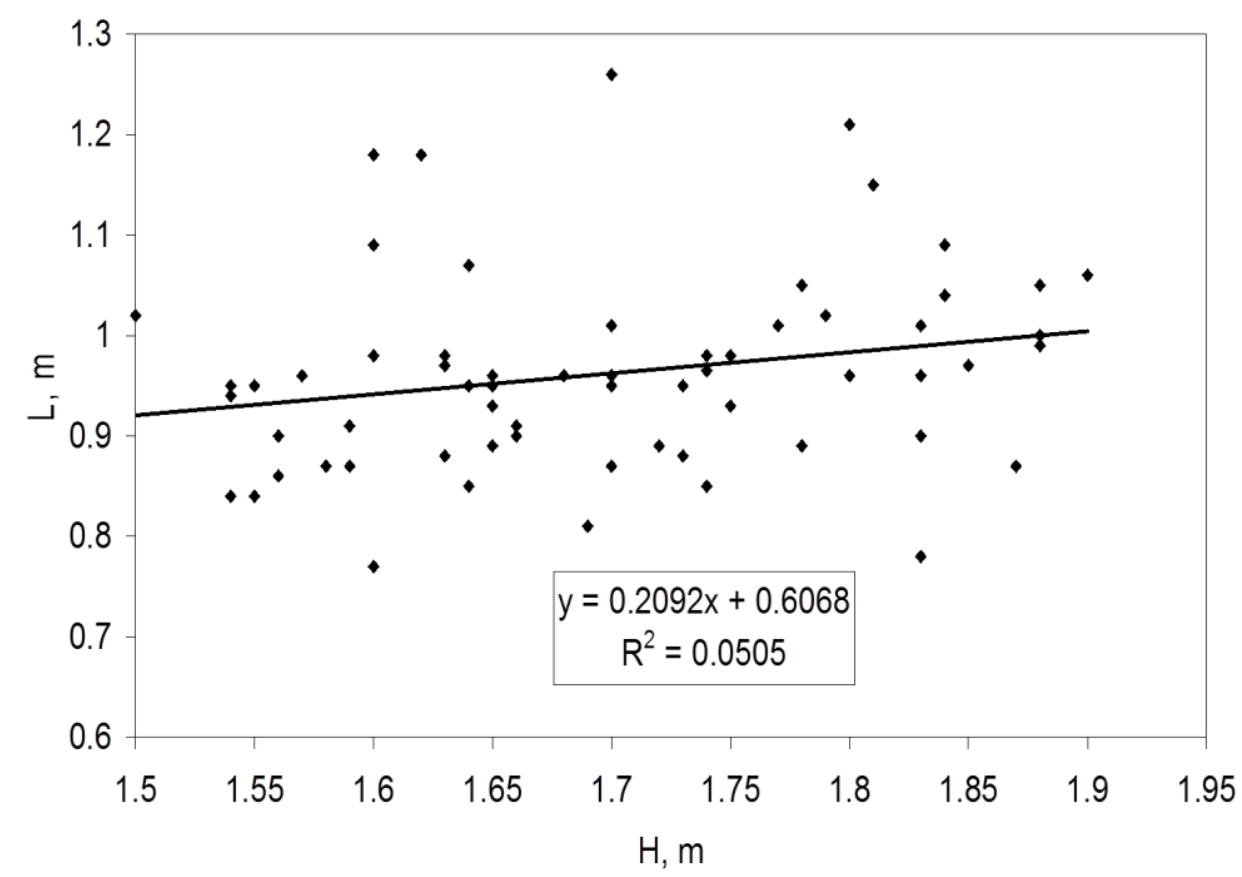

Figure 3. Dependence between body circumference L (m) and body height $\mathrm{H}(\mathrm{m})$. Insignificant correlation $\mathrm{p}>$ 0.05 . 


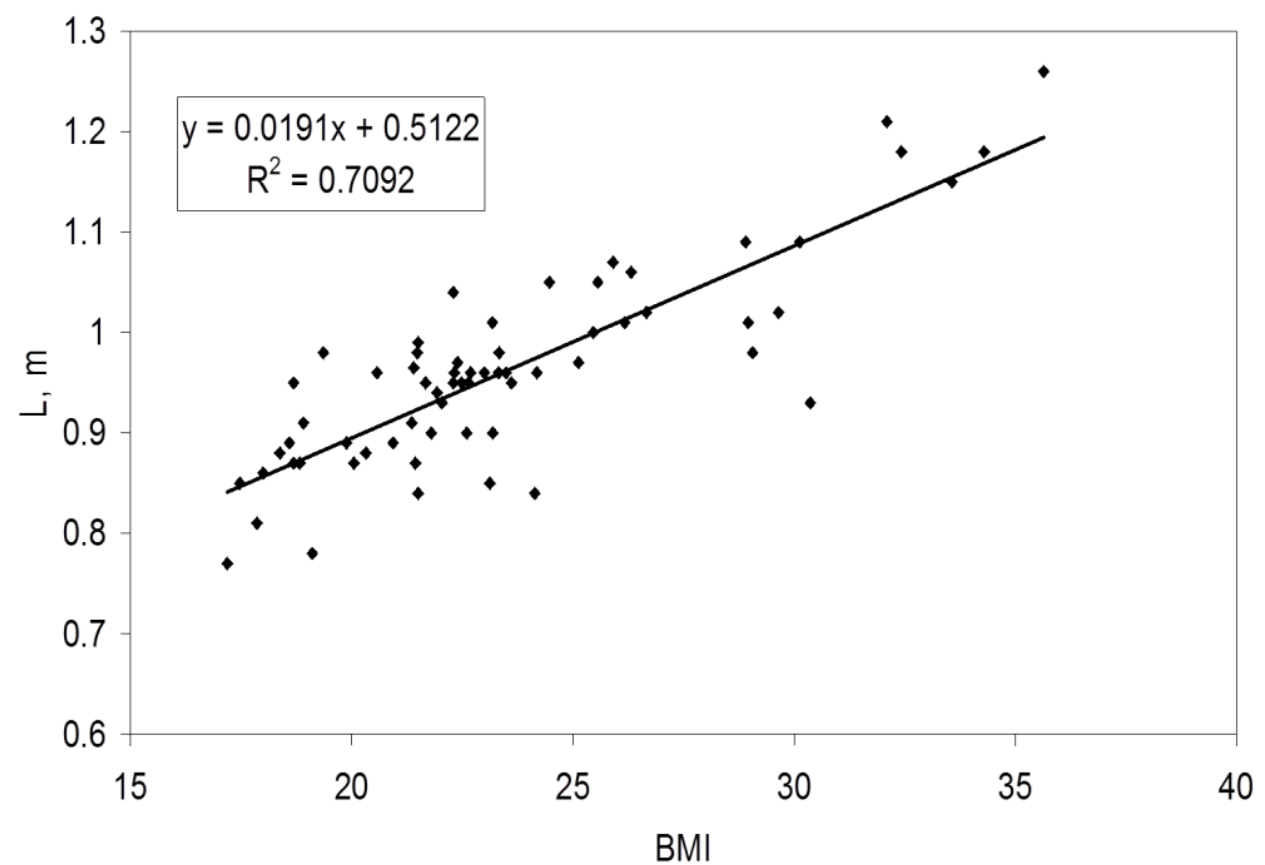

Figure 4. Relationship between body circumference L $(\mathrm{m})$ and BMI $\left(\mathrm{kg} / \mathrm{m}^{2}\right)$. Level of statistical significance $\mathrm{p}<$ 0.00001 .

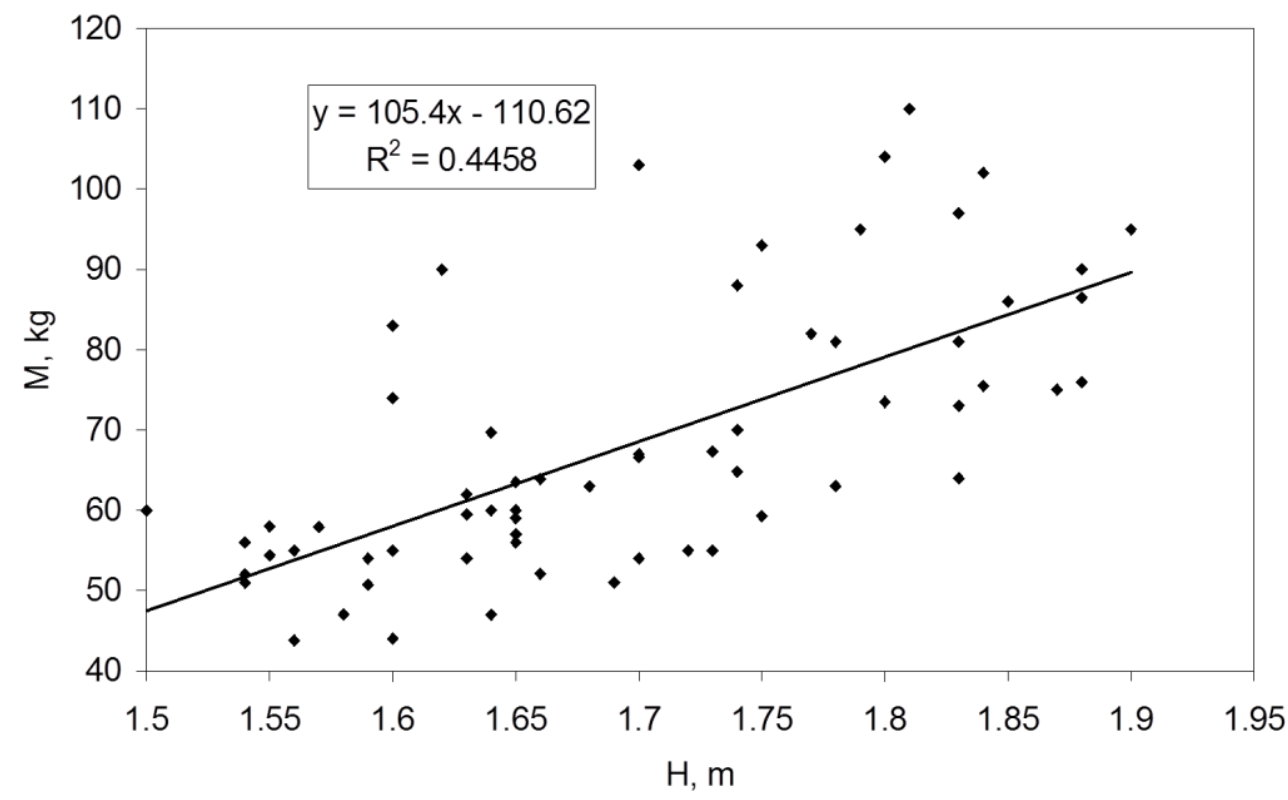

Figure 5. Dependence between body mass $\mathrm{M}(\mathrm{kg})$ and body height $\mathrm{H}(\mathrm{m})$. Level of statistical significance $\mathrm{p}<$ 0.00001 .

Table 2 presents the studied dependencies and their correlation coefficients.

Table 2. The studied bodily dependencies and their correlation coefficients

\begin{tabular}{|l|l|l|l|}
\hline $\begin{array}{l}\text { Measured } \\
\text { values }\end{array}$ & Statistical relationship & Correlation coefficients & Significant level \\
\hline L-M & $\mathrm{L}=0.0044 \mathrm{M}+0.6613$ & $\mathrm{R}=0.7464$ & $\mathrm{p}<0.00001$ \\
\hline $\mathrm{L}-\mathrm{H}$ & $\mathrm{L}=0.2092 \mathrm{H}+0.6068$ & $\mathrm{R}=0.2247$ & $\mathrm{p}>0.05$ \\
\hline $\mathrm{L}-\mathrm{BMI}$ & $\mathrm{L}=0.0191 \mathrm{BMI}+0.5122$ & $\mathrm{R}=0.8421$ & $\mathrm{p}<0.00001$ \\
\hline $\mathrm{M}-\mathrm{H}$ & $\mathrm{M}=105.4 \mathrm{H}-110.62$ & $\mathrm{R}=0.6677$ & $\mathrm{p}<0.00001$ \\
\hline
\end{tabular}




\section{DISCUSSION}

Interestingly, from Table 2 it can be observed that there is no statistically significant relationship between body circumference and its height - the correlation coefficient is relatively low $(\mathrm{R}=0.22)$, the level of statistical significance is $p>0.05$. Therefore, it can be considered that the two parameters of the body are practically unrelated. At different heights of the body, close circumferences of the body and vice versa can be observed.

It is known that the criterion for abdominal obesity is the circumference of the waist, which is measured horizontally around the middle of the body and represents the distance from the hip ridge of the pelvic floor to the lower end of the last rib [4].The larger the waist circumference, the higher the risk of cardiovascular disease. In our study, we measured the circumference of the body in the cross section of the equal torques of the upper and lower body, which also falls from the hip ridge of the upper of the pelvis to the lower end of the last rib. In this way we have fixed a specific place in the human body in which we believe that the waist circumference is the most representative. In this case, due to the high correlation coefficient $(0.8421)$ between the circumference of the body L / i.e. waist (s) and body mass index (BMI), it can be concluded that these body characteristics are related parameters with a level of statistical significance $\mathrm{p}<0.00001$.

This is a new result that has not been reported in the scientific literature. The obtained results can find applications in solving various scientific problems $[5,6]$.

\section{CONCLUSIONS}

A parametric linear regression analysis of the statistical relationship between body parameters (a, b, c, d) was performed:

a. Circumference (L) and body weight (M)

b. Circumference $(\mathrm{L})$ and body height $(\mathrm{H})$

c. Circumference (L) and body mass index (BMI)

d. Bodyweight $(\mathrm{M})$ and body height $(\mathrm{H})$

Student t-test was performed for each of these 4 regression relationships.
It was found that with the exception of the relationship between circumference (L) and body height $(\mathrm{H})$, the remaining relationships were statistically significant with a level of statistical significance $\mathrm{p}<0.00001$.

At a relatively high correlation coefficient $(\mathrm{R}=$ 0.7464 ) between the circumference of the body $\mathrm{L}$ (in the cross section of equal torques) and the mass of the body $\mathrm{M}$ and a low correlation coefficient $(0.2247)$ between the circumference of the body $\mathrm{L}$ and the height of the body $\mathrm{H}$, a high correlation coefficient is obtained $(0.8421)$ between the body circumference and the BMI.

A correlation coefficient (0.6677) was observed between body mass $\mathrm{M}$ and body height $\mathrm{H}$, which is less than that between body circumference and body mass (0.7464).

The level of statistical significance (p) of the found linear correlations between the circumference of the body L with the mass of the body $\mathrm{M}$, the height of the body $\mathrm{H}$ and the body mass index BMI is $p<0.00001$.

\section{REFERENCES}

1. Nuttall, F.K., Body Mass Index, Obesity, BMI, and Health: A Critical Review. Nutr. Today, 50, 117-128, 2015.

2. Atanasov, A.T., Method for determining the human body-mass center. Trakia Journal of Sciences, 2020 (in press).

3. Fuller H.Q., Fuller, R. M., and R.G. Fuller. Physics including human applications. Harper and Row Publishers 1978.

4. Yumuk, V., Tsigos, C., Fried, M., Schindler, $\mathrm{K}$. and L. Busetto, European guidelines for obesity management in adults, Obes Facts, 8, 402-424. 2015.

5. Atanasov, A., Todorova, M., Valev, D. and R. Todorova, Alometric relationships between the body-mass index, mass to surface ratio and the length of pregnancy in some mammals. Trakia Journal of Sciences, 12, 70-73, 2014.

6. Paskaleva, R. and A. T. Atanasov, Mathematic modeling of the Muskov quadragle for the evaluation of the muscle disorders in children and adults. AIP Conference Proceedings, 2075, 170029, 2019. https://doi.org/10.1063/1.5091394. 